P25 (continued)

Conclusions and Implications: Comparing quantitative network parameters (i.e. density and centrality) with other capacity building assessments will allow us to determine how specific modifications to the network (e.g. increasing density and/or centrality or restructuring the network geometry) may predict and improve coalition effectiveness over time. This novel methodology can be used for long-term evaluation and planning for local, state, and regional coalitions.

Funding: Center for Disease Control and Prevention

\section{P26 "Village Lunch Table" for the Korean Elderly in Rural Areas - A Pilot Program}

Yourim Choi, BA, RD, Myongji University;

Youngmi Lee, PhD; Youngsuk Lim, PhD, RD;

Kyungeun Lee, PhD, RD, Seoul Women's University; Changhee You,PhD, RD; Haeryun Park,PhD, RD, hrpark@ mju.ac.kr, Myongji University, 116 Myongji-ro, Cheoin$\mathrm{gu}$, Yongin city, Gyeonggi-do, Republic of Korea 17058

Objective: To develop and deliver a comprehensive nutrition program to improve the dietary quality and health of the elderly living in rural areas in South Korea.

Theory, Prior Research, Rationale: Compared to the elderly in urban areas, the elderly in rural areas are more vulnerable to inferior diets and loneliness, affected by the lack of public infrastructure, budget constraints, tendency to live alone, lack of health literacy, and geographical distances, etc.

Description: Forty different menus and nutrition education materials were developed and implemented, providing two free meals weekly for 10 weeks at 50 villages (delivered to about 1650 elderly). The cooking facilities of the community centers of each village were used. Helpers preparing meals and the elderly people were preeducated with nutrition materials on the five basic food groups, food hygiene, and dietary treatment for diabetes and hypertension.

Evaluation: The evaluation tools were surveys on recipient satisfaction, and diet quality comparison of meals provided versus the previous day's meals measured by the number of food (DVS) and food groups (GMVFD) consumed.

Conclusion and Implications: The satisfaction score was very high and the diet proved to be enhanced. This program of integrated meal service and nutrition education should be expanded to prevent the rural elderly from under nutrition and loneliness and to improve their health and quality of life.

Funding: Korean Ministry of Agriculture, Food, and Rural Affairs in 2016

\section{P27 WITHDRAWN}

\section{P28 Assessing Implementation Fidelity of Go for Green ${ }^{\circledR}$, a Military Performance Nutrition Initiative}

Alyssa Coleman, MPH, BS, CPH, alyssa.m.coleman2.ctr@ mail.mil, US Army Public Health Center, 5158 Blackhawk Road, APG-Edgewood, MD 21010; Chizoba Chukwura, MPH, BS, CPH, US Army Public Health Center; Karen Langlois, RDN, LD; Alyssa Dimatulac, BS; Bethany Belanger, PhD, RD, MAJ, LD, CSCS, Madigan Army Medical Center

Objective: To assess implementation of evidence-based nudging strategies in military dining facilities (DFACs), obtain feedback to refine future program implementation and examine changes to DFAC environments.

Target Audience: Since 2011, DFACs participated in the original version of Go for Green ${ }^{\circledR}(G 4 G)$, a military performance-nutrition program, utilizing standard food labels and print materials. In 2015, G4G was revamped with added nudging strategies and piloted over six months at seven DFACs within five continental U.S. Army installations.

Theory, Prior Research, Rationale: Food consumer research shows nudging empowers consumers to make healthier selections. Traffic light labeling is shown to effectively improve consumers' identification and selection of healthier items. Further studies show interventions using labeling in combination with choice architecture resulted in greater impact.

Description: A pre and post (photographs of DFAC serving areas) and post only (staff surveys, management interview) assessment of G4G implementation fidelity, barriers, facilitators, and environmental changes in DFACs.

Evaluation: After six months, results showed a 7\% increase in the proportion of food items labeled with G4G cards and a $4 \%$ increase in the level of incorporation of choice architecture indicators over baseline. Evaluation participants noted operational (e.g., staff attitudes and beliefs) and strategic (e.g., accountability, regulatory, and budget constraints) barriers to G4G implementation. Positive perceptions of G4G, program knowledge, and buy-in to partnering initiatives enhanced implementation success.

Conclusions and Implications: $G 4 G$ leadership is currently improving implementation guidance and introducing metrics to monitor program fidelity based on evaluation findings. Evaluation results may inform successful and sustainable nudging strategy implementation in military and comparable civilian food service environments.

Funding: None 